\title{
Cutaneous metastasis from prostatic adenocarcinoma - a rare presentation
}

\begin{abstract}
Prostatic carcinoma is common in elderly man but cutaneous metastasis of prostatic carcinoma is rare. The incidence is less than $1 \%$. A 55- year-old man presented with multiple cutaneous nodules around suprapubic region, inner aspect of both thigh and scrotum. Fine needle aspiration cytology and biopsy of cutaneous nodule showed metastatic adenocarcinoma. On digital rectal examination prostate was enlarged, hard, nodular and attached to rectal mucosa. Serum PSA value was markedly increased. TRUS biopsy specimen of prostate revealed adenocarcinoma (Gleason score $3+4$ ). In skin biopsy tumour is positive for cytokeratin. In our case FNAC provide an early clue to diagnose cutaneous metastasis of prostatic adenocarcinoma.
\end{abstract}

Volume 6 Issue I - 2018

\author{
Rathee VS, Patnaik P, Shaw D, Sartaj Wali \\ Khan, Trivedi S, Dwivedi US \\ Department Of Urology, Banaras Hindu University, India
}

\begin{abstract}
Correspondence: Vazir Singh Rathee, Department of Urology, Institute of Medical Sciences, Banaras Hindu University, Varanasi, U.P, Pin Code - 22100I, India, Tel 9416380676,

Email vs.ratheel2@gmail.com
\end{abstract}

Received: December 14, 2017 | Published: January 19, 2018

\section{Introduction}

Between $2 \%$ and $9 \%$ of visceral malignancies are responsible for cutaneous metastases. They usually occur in the advanced stage of malignancy and are associated with poor prognosis. ${ }^{1}$ Prostatic adenocarcinoma is common in elderly men with most common sites of metastasis being bone, lung, liver and lymph nodes, but cutaneous metastasis of prostatic adenocarcinoma is rare, the incidence is less than $1 \%{ }^{2}$ Skin metastases from prostate cancer are an ominous finding and most patients die within 6 months. The skin lesions are usually asymptomatic and lower abdomen, genitalia and thighs are most often involved.

\section{Methods and materials}

We report a 55 year old male who presented with multiple papulonodular lesions in suprapubic region, inner aspect of both thighs \& in the scrotum. The nodules were $0.3-1.5 \mathrm{~cm}$ in size. On local examination the nodules were fleshly in color, firm, smooth surfaced $\&$ subcutaneous in location and free from deep tissue. FNAC from the nodules showed adenocarcinoma. Then a search for the primary site was made which on clinical examination patient had history of thin stream, decreased flow, dysuria, hesitancy, nocturia \& loss of appetite but had no h/o hematuria. On DRE prostate was found to be enlarged, hard, nodular \& fixed to rectal wall mucosa. Serum PSA level of the patient was $45.4 \mathrm{ng} / \mathrm{ml}$. TRUS guided biopsy of prostate and biopsy of skin nodule was done. HPE of prostate revealed high grade adenocarcinoma (gleason score $3+4$ ). Biopsy of skin nodule showed infiltration by the tumor cells. Bone scan was negative. CT scan of the patient was not done.

\section{Results}

Patient was put on ADT therapy. PSA response was good. It came to $<1 \mathrm{ng} / \mathrm{ml}$. There was regression in the size of cutaneous nodules. But patient died after six months of therapy due to myocardial infarction and heart failure. ${ }^{3}$

\section{Discussion}

Prostatic carcinoma is common cancer in elderly men. It mostly metastasis to bone, lung, liver, adrenal and lymph nodes. Metastasis to skin is rare and accounts for less than $1 \%$ of cutaneous metastases, ${ }^{2}$ with less than 80 cases published in the literature. ${ }^{4,5}$ Clinically, patients present as asymptomatic papule, nodule or occasionally sclerodermoid lesion over suprapubic region, lower abdominal area, inner aspect of thigh and genitalia. ${ }^{6}$ Rare site of cutaneous metastasis include chest, scalp and face. ${ }^{1}$ The probable route of spread are dissemination vialymphatics and spread through perineural lymphatics. ${ }^{6,7}$ The cutaneous metastasis may resemble angiosarcoma, cellulitis, mammary Paget's disease, sebaceous cyst, Sister Joseph nodule, basal cell carcinoma, pyoderma, morphea, and trichoepithelioma. ${ }^{6}$ The definite diagnosis is done by skin biopsy. The tumour cells show positivity for PSA and cytokeratin. The serum PSA levels are also markedly elevated in these cases. The cutaneous metastasis represents advanced stage of the disease and associated with poor prognosis. Most of the patients die within six months of diagnosis. ${ }^{3}$ The treatment at this stage is palliative care which includes keeping the lesion dry and clean (Figure $1 \&$ Figure 2).

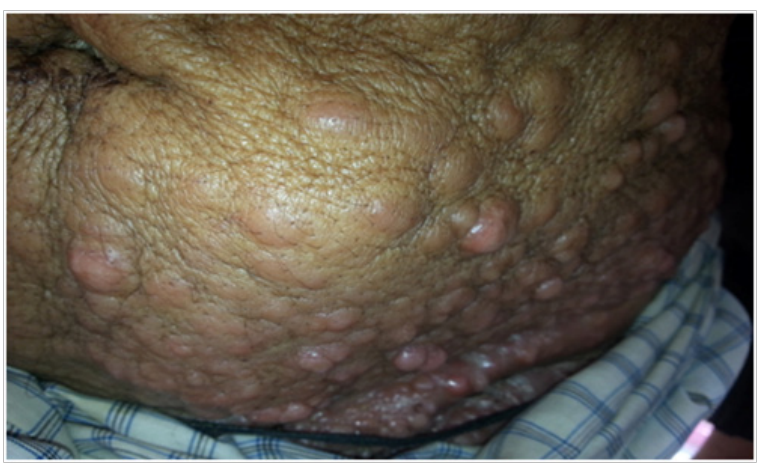

Figure I 55 years old male presenting with multiple papulonodular lesions in suprapubic region and anterior abdominal wall.

\section{Conclusion}

Prostate carcinoma is usually adenocarcinoma and has a high metastatic potential. It usually spreads to bones, liver, and lungs. Spread occurs either contiguously or via lymphatics or blood vessels; it often occurs through the vertebral-venous system. The mechanism of skin involvement is not well understood, but suggested routes include embolization of the vessels, dissemination via lymphatics and spread through perineural lymphatics. 


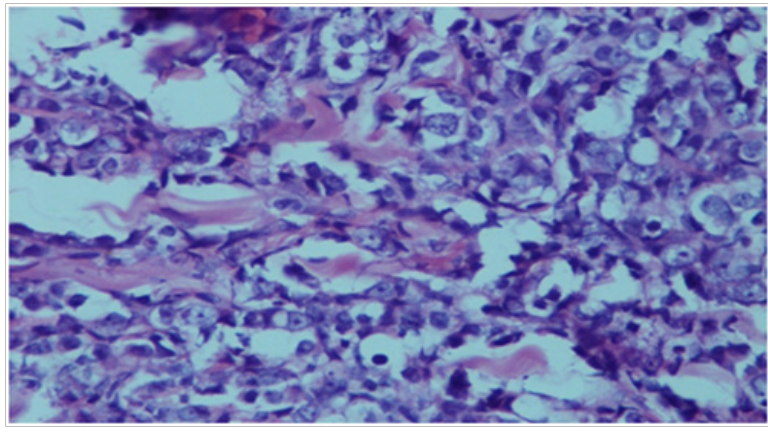

Figure 2 Histopathology of the skin nodule showing infiltration by prostatic adenocarcinoma.

\section{Acknowledgements}

None.

\section{Conflicts of interest}

None.

\section{References}

1. Luis Paz-Ares L, Olivia E, Carey RW, et al. Skin lesions in malignancy: case 2: skin metstases from prostate adenocarcinoma. J Clin Oncol. 2001;19(7):2099-2100.

2. Pique Duran E, Paradela A, Farina MC, et al. Cutaneous metastases from prostatic carcinoma. J Surg Oncol. 1996;62(2):144-147.

3. Pistone G, Pistone A, Arico M, et al. Multiple cutaneous metastases in the chest from prostatic carcinoma. Case Rep Dermatol. 2013;5(1):2730 .

4. Schwartz RA. Cutaneous metastatic disease. $J$ Am Acad Dermatol. 1995;33(2 Pt 1):161-182.

5. Lookingbill DP, Spangler N, Sexton FM. Skin involvement as the presenting sign of internal carcinoma. A retrospective study of 7,316 cancer patients. J Am Acad Dermatol. 1990;22(1):19-26.

6. Reddy S, Bang RH, Contreras ME. Telangiectatic cutaneous metastasis from carcinoma of the prostate. Br J Dermatol. 2007;156(3):598-600.

7. Pal D, Talwar V, Doval DC, et al. Cutaneous metastasis in prostatic carcinoma. Indian J Dermatol Venerol Leprol. 2009;75(3): 311-312. 